Article

\title{
Guidelines for Optimal Selection of Subcritical Low-Temperature Geothermal Organic Rankine Cycle Configuration Considering Reinjection Temperature Limits
}

\author{
Chao Zhang ${ }^{1,2}$, Jinglun Fu ${ }^{1,3, *}$, Pengfei Yuan ${ }^{2}$ and Jianjun Liu ${ }^{1,3, *}$ \\ 1 Institute of Engineering Thermodynamics, Chinese Academy of Sciences, Beijing 100190, China; \\ czhangxj83@163.com \\ 2 Tianjin Key Laboratory for Advanced Mechatronic System Design and Intelligent Control, \\ Tianjin 300384, China; yuan19950109@126.com \\ 3 University of Chinese Academy of Sciences, Beijing 100049, China \\ * Correspondence: fujl@iet.cn (J.F.); jjl@mail.etp.ac.cn (J.L.); Tel.: +86-010-8254-3061 (J.F.)
}

Received: 8 September 2018; Accepted: 22 October 2018; Published: 24 October 2018

\begin{abstract}
General guidelines are proposed to select the optimal subcritical organic Rankine cycle configuration considering reinjection temperature limits for a low-temperature geothermal brine power plant. Saturated/superheated, non-regenerative/regenerative cycles are investigated. Evaporating temperature and overheating degree at the turbine inlet are selected as design variables, and highest plant exergy efficiency is pursued for current optimizations. Through theoretical analysis of mathematical modelling and typical case studies, a simple optimization approach is presented. The new approach consists of up to three judgements on reinjection temperature and evaporating temperature in comparison two optimization calculations along the saturated line and along the given reinjection temperature line. The potential optimal cycle configurations are saturated non-regenerative cycle, saturated regenerative cycle and superheated regenerative cycle. Then, this new optimization approach is applied to obtain optimal cycle configuration and relevant working condition. The working fluids investigated are R245fa, R1234ze(Z), isopentane, and isobutane. The saturated non-regenerative cycle is the optimal cycle when the reinjection temperature limit is equal or less than the optimal reinjection temperature with no reinjection constraint. Otherwise, the reinjection temperature limit influences not only the optimal cycle configuration but also the optimal working condition. Working fluid isobutane always achieves highest plant exergy efficiency for optimal cycles with either reinjection temperature limit.
\end{abstract}

Keywords: geothermal power plant; organic Rankine cycle; saturated cycle; regenerative cycle; plant exergy efficiency

\section{Introduction}

Low temperature geothermal brine in range of $90-150{ }^{\circ} \mathrm{C}$ shows a large potential for electrical power generation [1]. Organic Rankine Cycle (ORC) systems have been developed over the past several decades as a first choice for their simple construction, high thermodynamic performance and easy maintenance [2], but the efficiency of ORC systems is relatively low because of the low temperature of geothermal brine, and as a consequence, the cycle configuration must be selected and designed carefully to obtain optimum thermodynamic performances.

Many cycle configurations [3-6] have been proposed and investigated, including single/dual pressure, saturated/superheated, non-regenerative/regenerative and subcritical/supercritical cycles, 
et al. As a common practice in geothermal brine power plants, the ORC system is designed as a single pressure subcritical cycle with a regenerator $[7,8]$. The regenerator used here is to recover the exhaust heat energy and thus to increase the cycle efficiency, but the regenerator can also decrease the utilization of the heat source, and the net power output or the plant thermal efficiency may not be improved $[9,10]$. Yamamoto et al. [11] carried out both numerical simulations and experimental tests on the saturated/superheated subcritical ORC systems and concluded that saturated vapor for organic fluid at the turbine inlet gives a higher turbine power output than overheating vapor. Several subsequent studies $[12,13]$ also suggested that the saturated cycle is the optimal solution from the view of thermodynamic performance. Chagnon-Lessard et al. [14] founded that saturated vapor at the turbine inlet for dry working fluid gives maximized specific power output, but overheating vapor for wet working fluid. It is noticed that the previous research conclusions in [9-14] are all drawn with the assumption that there is no constraint of heat source outlet temperature.

In fact, the brine reinjection temperature is always constrained with a minimum allowable value to limit the deposit of silica compounds and consequent fouling of the heat exchangers. There are few research works [15-17] with consideration of the effect of the reinjection temperature limit. Because the reinjection temperature limit with value of $75^{\circ} \mathrm{C}$ is higher than the reinjection temperature in the case without constraint, Walraven et al. [15] concluded that the geothermal brine must be cooled to $75^{\circ} \mathrm{C}$ and the regenerative cycle is superior to the non-regenerative cycle. In spite of different definition for plant exergy efficiency and reinjection temperature limit, Astolfi et al. [16] drew a similar conclusion with the reinjection temperature limit of $70^{\circ} \mathrm{C}$. Clark et al. [17] investigated the influence of two reinjection temperature limits of $70^{\circ} \mathrm{C}$ and $90^{\circ} \mathrm{C}$. They concluded that reinjection temperature limit can significantly reduce the maximum achievable specific power output, and there are no over-arching design guidance for the optimal ORC configuration of geothermal brine power plants. Chen et al. [18] also obtained maximum heat power input to the ORC system by setting constant minimum allowable heat source outlet temperature for waste heat recovery. As a matter of fact, the geothermal brine heat source is classified as a typical open type heat source by the definition in [19], which is featured with minimum allowable reinjection temperature. But the treatment of reinjection temperature in [15] means a great reduction of available working points, which may not achieve the global maximum thermodynamic performance for a specific ORC system. Borsukiewicz-Gozdur [19] compared the plant exergy efficiencies between the saturated non-regenerative and regenerative cycles with a much lower reinjection temperature of $40{ }^{\circ} \mathrm{C}$, and concluded that the net power output is not increased by application of regenerator. This conclusion is contrary to that with reinjection temperature limits of $75^{\circ} \mathrm{C}$ in [15] and $70{ }^{\circ} \mathrm{C}$ in [16]. Hence, the optimal cycle configuration strongly depends on the value of reinjection temperature limit.

Based on the survey work [20] on 26 geothermal brine power plants around the world, the reinjection temperature limit varies from $50{ }^{\circ} \mathrm{C}$ to $100{ }^{\circ} \mathrm{C}$ in practice. Despite several pioneering works [15-17] have been carried out, the influence of the reinjection temperature limit is still needed to be fully investigated. The aim of the present study is to: (1) investigate the effect of reinjection temperature limit covering a wider temperature range, (2) find an optimal subcritical cycle configuration and obtain the maximum plant exergy efficiency for a geothermal brine heat source at $150^{\circ} \mathrm{C}$ using R245fa, R1234ze(Z), isopentane and isobutane as working fluids.

\section{ORC System Modelling and Theoretical Analysis}

Single pressure level subcritical organic Rankine cycles in saturated/superheated, non-regenerative/regenerative configurations are investigated in the present study. Figure 1 shows the schematic layout of a regenerative ORC system, which consists of a turbine, two pumps (feed pump, and circulating pump), an evaporator, a condenser, and a regenerator. The regenerator is used mainly to recover the heat energy from the exhaust vapor at the turbine outlet. For a non-regenerative cycle, there is no regenerator in the system. 


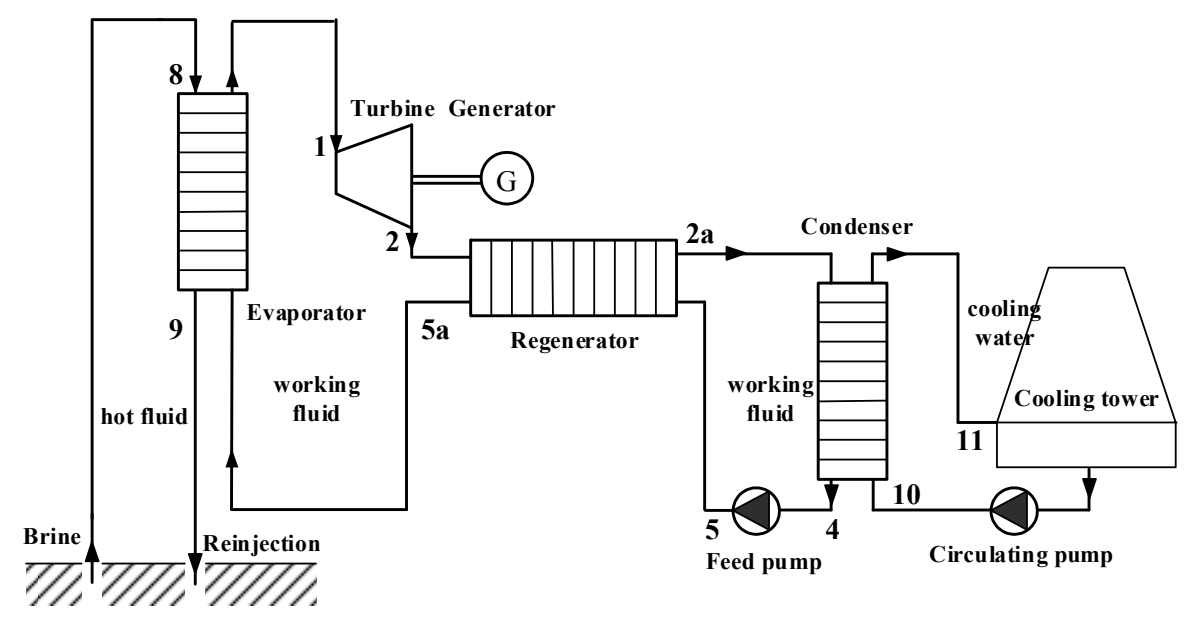

Figure 1. Schematic layout of the regenerative cycle.

Figure 2 depicts the $T$-s diagrams of the superheated non-regenerative/regenerative cycles. There are mainly four thermodynamic processes for the non-regenerative cycle, i.e., the process 1-2 (expansion in the turbine), the process 2-3-4 (an exothermic process, the heat in the working fluid is absorbed by the cold fluid at a constant lower pressure in the condenser), the process $4-5$ (pumping in the feed pump), and the process 5-6-7-1 (an endothermic process, the working fluid absorbs heat form hot fluid at a constant higher pressure). Besides, the process 8-6h-9 (relevant to the process 5-6-7-1) depicts the decreasing change trend of the hot fluid temperature, and the process 10-3c-11 (relevant to the process 2-3-4) describes the increasing profile of the cold fluid temperature. Three pinch point temperature differences in the evaporator $\Delta T_{\mathrm{pp}, \mathrm{e}}$, in the condenser $\Delta T_{\mathrm{pp}, \mathrm{c}}$, in the regenerator $\Delta T_{\mathrm{pp}, \mathrm{c}}$ and the overheating degree at the turbine inlet $\Delta T_{1, \text { oh }}$ are also shown in Figure 2. Note that, the pinch point in the evaporation is assumed to be located at the beginning of the isothermal evaporation section, i.e., state 6, which is commonly adopted in many previous studies [9-11]. Another possible location at the beginning of the preheating section in the evaporator, which shows a temperature difference higher than about $40^{\circ} \mathrm{C}$ between the heat source temperature and the critical temperature of the working fluid, is not suitable in present study based on the suggestion by Vivian et al. [21].

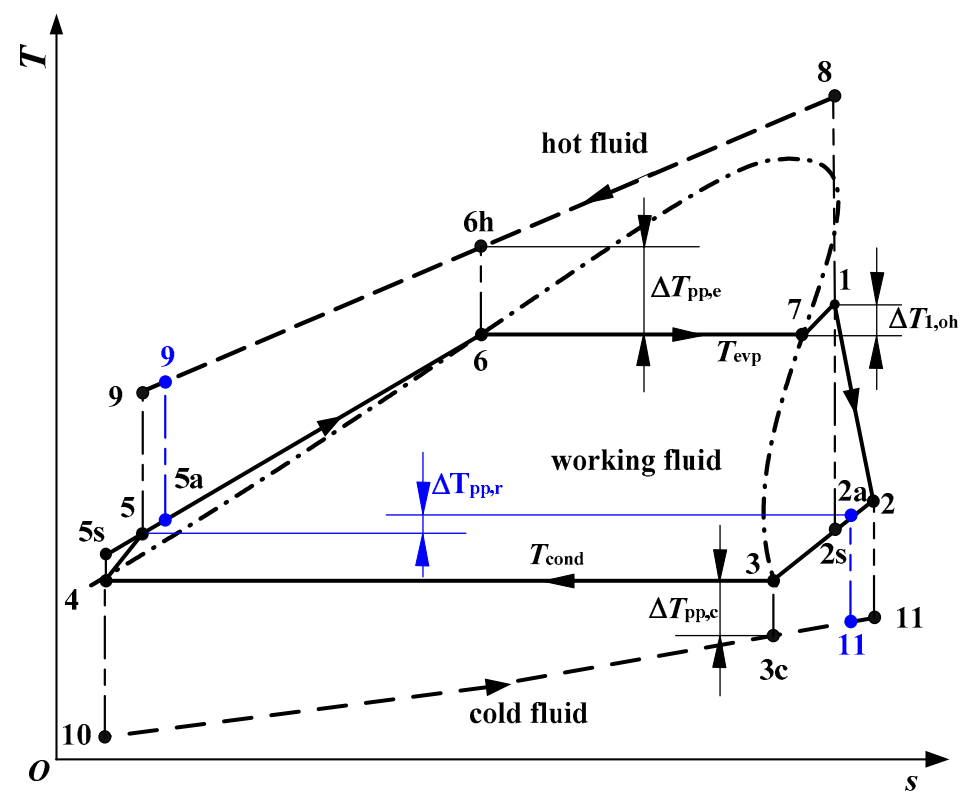

Figure 2. $T$-s diagram of non-regenerative/regenerative ORC systems. 
For the regenerative cycle, state points 5 and 2 at the evaporator inlet and at the condenser inlet change to $5 \mathrm{a}$ and 2a, respectively. Accordingly, the state points 9 and 11 at brine reinjection and the cooling fluid outlet both have higher temperatures than these for non-regenerative cycle due to the regenerator. State points 1 and 7 simply merge to one for the saturated cycle.

In order to simplify the mathematical modeling, two assumptions are made as following, (i) the cycle is always operated under steady states, (ii) pressure drops in the evaporator, the condenser, the regenerator and the connecting pipelines are all omitted. Based on the mass conservation and energy conservation of the ORC model, the mass flow rates of the working fluid and the cold fluid can be calculated as follows:

$$
\begin{gathered}
m_{\mathrm{wf}}=m_{\mathrm{hf}} \cdot \frac{h_{8}-h_{6 \mathrm{~h}}}{h_{1}-h_{6}}=m_{\mathrm{hf}} \cdot \frac{c_{\mathrm{p}, \mathrm{hf}}\left(T_{8}-T_{\mathrm{ev}}-\Delta T_{\mathrm{pp}, \mathrm{e}}\right)}{h_{1}-h_{7}-\Delta h_{\mathrm{ev}}} \\
m_{\mathrm{cf}}=m_{\mathrm{wf}} \cdot \frac{h_{3}-h_{4}}{h_{3 c}-h_{10}}=m_{\mathrm{wf}} \cdot \frac{\Delta h_{\mathrm{cond}}}{c_{\mathrm{p}, \mathrm{cf}}\left(T_{\mathrm{cond}}-\Delta T_{\mathrm{pp}, \mathrm{c}}-T_{10}\right)}
\end{gathered}
$$

The electrical power output by the turbine $W_{\mathrm{t}}$, and the electrical power consumption by the feed pump $W_{\mathrm{p}}$ and the circulating pump $W_{\mathrm{pc}}$ are defined as follows:

$$
\begin{gathered}
W_{\mathrm{t}}=m_{\mathrm{wf}} \eta_{\mathrm{g}} \eta_{\mathrm{m}} \eta_{\mathrm{t}}\left(h_{1}-h_{2 \mathrm{~s}}\right) \\
W_{\mathrm{p}}=\frac{m_{\mathrm{wf}}\left(h_{5 \mathrm{~s}}-h_{4}\right)}{\eta_{\mathrm{p}} \eta_{\mathrm{p}, \text { motor }}} \\
W_{\mathrm{pc}}=\frac{m_{\mathrm{cf} g} \mathrm{~g}}{\eta_{\mathrm{pc}} \eta_{\mathrm{pc}, \text { motor }}}
\end{gathered}
$$

$H$ is the pumping head of the circulating pump with the value of $20 \mathrm{~m}$ in the present study.

Then, the net electrical power output of the ORC system is conserved as:

$$
W_{\text {net }}=W_{\mathrm{t}}-W_{\mathrm{p}}-W_{\mathrm{pc}}
$$

Finally, the plant exergy efficiency $\eta$, which is used to evaluate the overall utilization degree of the heat source, is defined by:

$$
\eta=\frac{W_{\text {net }}}{m_{\mathrm{hf}}\left(h_{8}-h_{0}\right)-T_{0}\left(s_{8}-s_{0}\right)}
$$

In the present study, the reference exergy is the maximum available exergy from the heat source when the temperature and the pressure of the geothermal brine decreases to ambient temperature and pressure. The ambient temperature $T_{0}=20^{\circ} \mathrm{C}$ and ambient pressure $p_{0}=101.3 \mathrm{kPa}$ are taken as the reference values.

Substituting Equations (1)-(6) into Equation (7), the following expression is derived:

$$
\eta=\frac{\frac{c_{\mathrm{p}, \mathrm{hf}}\left(T_{8}-T_{\mathrm{ev}}-\Delta T_{\mathrm{pp}, \mathrm{e}}\right)}{h_{8}-h_{0}-T_{0}\left(s_{8}-s_{0}\right)}\left[\eta_{\mathrm{m}} \eta_{\mathrm{t}}\left(h_{1}-h_{2 \mathrm{~s}}\right)-\frac{\left(h_{5 \mathrm{~s}}-h_{4}\right)}{\eta_{\mathrm{p}} \eta_{\mathrm{p}, \mathrm{motor}}}-\frac{\Delta h_{\mathrm{cond}} g H}{c_{\mathrm{p}, \mathrm{f}} \eta_{\mathrm{pc}} \eta_{\mathrm{pc}, \text { motor }}\left(T_{\mathrm{cond}}-\Delta T_{\mathrm{pp}, \mathrm{c}}-T_{10}\right)}\right]}{h_{1}-h_{6}}
$$

It can be clearly shown in Equation (8) that the plant exergy efficiency increases with the decreasing of the pinch point temperature differences in the evaporator and the condenser, the increasing of turbine efficiency, the feed pump efficiency and the circulating pump efficiency. Turbine efficiency is an important parameter for the ORC system. If the turbine efficiency is treated as a constant value, the only difference between the superheated cycle and the saturated cycle is the higher specific enthalpy at the turbine inlet resulted by the overheating vapor. Although a definitive relationship between the plant exergy efficiency and turbine inlet overheating degree can not be drawn from rigid mathematical analysis, previous studies [11-13] show that the saturated cycle exhibits a higher plant exergy efficiency 
than the superheated cycle under the same working condition. In present study, the turbine efficiency is treated as a variable, which depends on the specific turbine inlet and outlet conditions. Thus, the effect of turbine inlet overheating degree on the plant exergy efficiency will be studied in Section 4 . Besides, the relationship between the plant exergy efficiency and the evaporating temperature is not obvious only based on Equation (8), which will be also investigated under the typical working conditions in Section 4.

It is needed to note that Equations (1)-(7) do not depend on the presence of regenerator. The main difference between the non-regenerative and regenerative cycles is the reinjection temperature as shown in Figure 2. The reinjection temperatures for the non-regenerative and the regenerative cycles are calculated as, respectively:

$$
\begin{gathered}
T_{9}=T_{8}-\frac{h_{1}-h_{5}}{h_{1}-h_{6}}\left(T_{8}-T_{\mathrm{ev}}-\Delta T_{\mathrm{pp}, \mathrm{e}}\right) \\
T_{9, \mathrm{r}}=T_{8}-\frac{h_{1}-h_{5}-\left(h_{2}-h_{2 \mathrm{a}}\right)}{h_{1}-h_{6}}\left(T_{8}-T_{\mathrm{ev}}-\Delta T_{\mathrm{pp}, \mathrm{e}}\right)
\end{gathered}
$$

Based on Equations (9) and (10), the reinjection temperature decreases with the increasing of evaporating temperature $T_{\mathrm{ev}}$ and the increasing of overheating degree $\Delta T_{1, \mathrm{oh}}$ at the turbine inlet for both non-regenerative and regenerative cycles.

If the reinjection temperature is unlimited, the highest value of maximum plant exergy efficiency occurs for the saturated cycle only, and there is no difference between the non-regenerative and regenerative cycle in terms of the maximum plant exergy efficiency. Taking the additional heat transfer area of the regenerator and the ORC system complexity into consideration, the saturated non-regenerative cycle is a preferred option. But when the reinjection temperature limit is concerned, which cycle configuration is the best selection in terms of the plant exergy efficiency? When the relevant optimal reinjection temperature $T_{9, \text { opt }}$ (for saturated non-regenerative cycle without reinjection temperature limit) is equal to or higher than the specified reinjection temperature limit $T_{9, \text { lim }}$, there are no changes for the optimal working condition and the optimal cycle configuration. Recall that the reinjection temperature decreases with the increasing of evaporating temperature, if the reinjection temperature $T_{9, \mathrm{opt}}$ is lower than $T_{9, \mathrm{lim}}$, a definite conclusion can not be drawn based on theoretical analysis only. This question will be solved in the following section for a typical ORC system.

\section{ORC System Conditions and Constraints}

A low-temperature geothermal brine power plant with the typical parameters is selected in the present study to investigate the effect of reinjection temperature limit. The heat source has a temperature of $150{ }^{\circ} \mathrm{C}$, a pressure of $1500 \mathrm{kPa}$, and a mass flow rate of $10 \mathrm{~kg} / \mathrm{s}$. The heat sink is the cooling water with a temperature of $20^{\circ} \mathrm{C}$. The pinch point temperature differences in the evaporator, the condenser, and the regenerator are selected as $10^{\circ} \mathrm{C}, 5^{\circ} \mathrm{C}$ and $5^{\circ} \mathrm{C}$, respectively.

Turbine efficiency has a great influence on the optimal working condition and the thermodynamic performance. Several studies [22-24] have pointed out that the turbine efficiency with a constant value may mislead when determining the optimal working conditions for a specific ORC system. Hence, the turbine efficiency should be not arbitrarily fixed to a constant value but rather vary according to the operating conditions at the turbine inlet and outlet. A single stage radial turbine is used here for its compactness and high efficiency with a few $10 \mathrm{~kW}-100 \mathrm{~kW}$. The turbine efficiency used here is a function of the volumetric expansion ratio $V R$ and the size parameter $S P$ at relevant optimal specific speed, which was proposed in [25]. The definitions of the volumetric expansion ratio $V R$ and the size parameter $S P$ are given by the following equations:

$$
V R=\frac{V_{2 \mathrm{~s}}}{V_{1}}
$$




$$
S P=\frac{V_{2 \mathrm{~s}}^{0.5}}{\left(h_{1}-h_{2 \mathrm{~s}}\right)^{0.25}}
$$

The parameter $V R$ is preferred to the pressure ratio considering the compressibility of working fluid. The parameter $S P$ accounts for both volumetric flow rate at turbine outlet and isentropic specific enthaply drop across the turbine, which is also proportional to the actual turbine dimension [22]. Obviously, the volumetric expansion ratio $V R$ and the size parameter $S P$ can be calculated only by the thermal properties at working states 1 and $2 \mathrm{~s}$. Hence, the turbine efficiency in the present study is calculated based on the turbine efficiency map from the work of Perdichizzi and Lozza [25] for a single stage radial inflow turbine, which is shown in Figure 3. The turbine efficiency varies from 0.78 to 0.89 in the valid region $(S P=0.008-0.20 \mathrm{~m}, V R=1-10)$. It is noticing that turbine efficiency is lower with a small $S P$ and large $V R$ value, and higher with a large $S P$ and small $V R$ value.

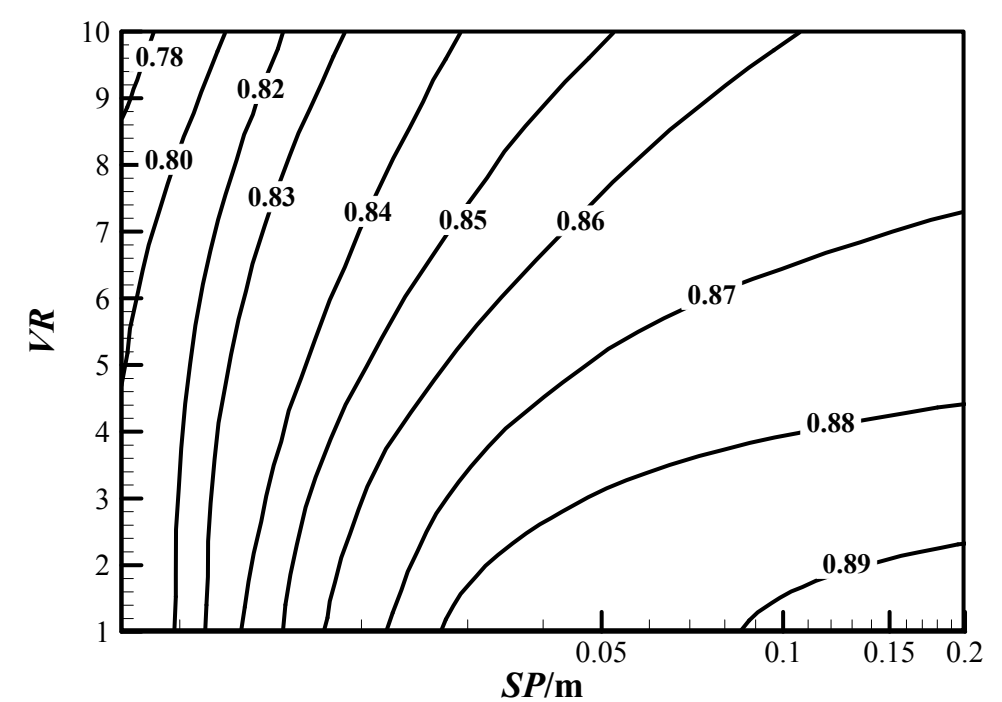

Figure 3. Turbine efficiency map (reproduced from Perdichizzi and Lozza [25]).

The feed pump efficiency and the circulating pump efficiency are 0.75 and 0.70 , respectively. Besides, the generator efficiency and the transmission efficiency between turbine and generator are both 0.95 . The motor efficiency for feed pump is calculated by the following equation [26]:

$$
\eta_{\mathrm{p}, \text { motor }}=0.75+0.115 \log _{10}\left(W_{\mathrm{p}} / 1000\right)-0.015\left[\log _{10}\left(W_{\mathrm{p}} / 1000\right)\right]^{2}
$$

The motor efficiency for the circulating pump is also calculated based on the Equation (13).

The condensing temperature is set to be a typical value of $30^{\circ} \mathrm{C}$. The minimum reinjection temperatures are limited to be $70^{\circ} \mathrm{C}, 75^{\circ} \mathrm{C}$ and $85^{\circ} \mathrm{C}$ respectively to cover a wider temperature range. In addition to the constraint of reinjection temperature limit, the dryness fraction of vapor must be larger than 0.95 in the expansion process 1-2 to minimize the wet vapor loss.

The ORC system conditions including heat source, sink, fixed values, and the constraints are summarized in Table 1. 
Table 1. System boundary conditions, fixed values and constraints.

\begin{tabular}{cc}
\hline Parameter & Value \\
\hline Geothermal brine temperature $T_{8}\left({ }^{\circ} \mathrm{C}\right)$ & 150,130 \\
Geothermal brine pressure $p_{8}(\mathrm{kpa})$ & 1500 \\
Mass flow rate of geothermal brine $m_{\mathrm{hf}}(\mathrm{kg} / \mathrm{s})$ & 10,20 \\
Evaporator pinch point temperature difference $\delta t_{\mathrm{pp}, \mathrm{e}}\left({ }^{\circ} \mathrm{C}\right)$ & 10 \\
Condenser pinch point temperature difference $\delta t_{\mathrm{pp}, \mathrm{c}}\left({ }^{\circ} \mathrm{C}\right)$ & 5 \\
Regenerator pinch point temperature difference $\delta t_{\mathrm{pp}, \mathrm{r}}\left({ }^{\circ} \mathrm{C}\right)$ & 5 \\
Turbine efficiency $\eta_{\mathrm{t}}(-)$ & Turbine efficiency map in Figure 3 \\
Feed pump efficiency $\eta_{\mathrm{p}}(-)$ & 0.75 \\
Circulating pump efficiency $\eta_{\mathrm{pc}}(-)$ & 0.70 \\
Transmission efficiencyof turbine $\eta_{\mathrm{m}}(-)$ & 0.95 \\
Generator efficiency $\eta_{\mathrm{g}}(-)$ & 0.95 \\
Motor efficiency for feed pump $\eta_{\mathrm{p}, \mathrm{motor}}(-)$ & Equation $(13)$ \\
Motor efficiency for circulating pump $\eta_{\mathrm{pc}, \text { motor }}(-)$ & 30 \\
Condensing temperature $T_{\mathrm{cond}}\left({ }^{\circ} \mathrm{C}\right)$ & $70,75,85$ \\
Reinjection temperature limit $T_{9, \text { lim }}\left({ }^{\circ} \mathrm{C}\right)$ & \\
\hline
\end{tabular}

Based on the previous experience of the low-temperature geothermal ORC power plants, four candidate working fluids R245fa and its substitution R1234ze(Z), isopentane, and isobutane are investigated. The main thermal properties of the selected working fluids are listed in Table 2. All the thermodynamic properties of the candidate working fluids are acquired from NIST REFPROP database. It is noticing that the condensing pressures are all higher than ambient pressure, which can avoid the utilization of vacuum facilities to keep vacuum circumstances in the condenser and the later expansion process. Moreover, the lower condensing pressure will result in higher volumetric expansion ratio in the turbine, thus reduce the turbine efficiency and the plant exergy efficiency. Hydrofluorocarbons working fluids R245fa and R1234ze(Z) show similar critical temperatures, critical pressures, condensing pressures and latent enthalpies at the evaporating temperature of $90^{\circ} \mathrm{C}$, but quite different 100 years global warming potentials (GWP). Working fluid R1234ze(Z), alkanes working fluids isopentane and isobutane have much lower GWPs compared with R245fa. Isopentane and isobutane have much higher latent enthaplies than the working fluids R245fa and R1234ze(Z). Besides, the flammability levels of isopentane and isobutane are higher than R245fa and R1234ze(Z).

Table 2. Thermal properties of selected working fluids.

\begin{tabular}{cccccc}
\hline Working Fluid & $\boldsymbol{T}_{\text {crit }}\left({ }^{\circ} \mathbf{C}\right)$ & $p_{\text {crit }}(\mathbf{k P a})$ & $\begin{array}{c}p_{\text {cond }}(\mathbf{k P a}) \\
\left(\boldsymbol{T}_{\text {cond }}=\mathbf{3 0}^{\circ} \mathbf{C}\right)\end{array}$ & $\begin{array}{c}\Delta \boldsymbol{h}_{\mathbf{e v}}(\mathbf{k J}) \\
\left(\boldsymbol{T}_{\mathbf{e v}}=\mathbf{9 0}{ }^{\circ} \mathbf{C}\right)\end{array}$ & $\begin{array}{c}\mathrm{GWP} \\
(\mathbf{1 0 0} \text { Years })\end{array}$ \\
\hline R245fa & 154.0 & 3651.0 & 177.8 & 143.92 & 1020 \\
R1234ze(Z) & 150.1 & 3533.0 & 210.2 & 155.01 & 7 \\
isopentane & 187.2 & 3378.0 & 109.2 & 286.33 & $\sim 20$ \\
isobutane & 134.7 & 3629.0 & 404.7 & 233.32 & 25 \\
\hline
\end{tabular}

The upper limit and lower limit of evaporating temperature and overheating degree at the turbine inlet are listed as follows:

$$
\begin{gathered}
T_{\mathrm{ev}, \text { min }} \leq T_{\mathrm{ev}} \leq T_{\mathrm{ev}, \text { max }}, T_{\mathrm{ev}, \text { min }}=T_{\mathrm{sta}}\left(p_{\text {cond }}+10 \mathrm{kPa}\right), T_{\mathrm{ev}, \text { max }}=\min \left[\left(T_{\text {crit }}-3^{\circ} \mathrm{C}\right),\left(T_{8}-\Delta T_{\mathrm{pp}, \mathrm{e}}\right)\right] \\
0 \leq \Delta T_{1, \mathrm{oh}} \leq \Delta T_{1, \mathrm{oh}, \max }, \Delta T_{1, \mathrm{oh}, \text { max }}=\min \left(T_{8}-\Delta T_{\mathrm{pp}, \mathrm{e}}-T_{\mathrm{ev}}, 30^{\circ} \mathrm{C}\right)
\end{gathered}
$$

The minimum evaporating temperature is the relevant saturated temperature at the pressure higher than the condensing pressure by $10 \mathrm{kPa}$. Due to the constraint of evaporator pinch point temperature difference, turbine inlet temperature must be less than or equal to $T_{8}-\Delta T_{\mathrm{pp}, \mathrm{e}}$ (the temperature difference between geothermal brine temperature and evaporator pinch point temperature difference). Meanwhile, evaporating temperature must be less $3{ }^{\circ} \mathrm{C}$ than the critical temperature of 
working fluid to keep stable thermal properties based on the suggestion in [24]. Hence, the maximum evaporating temperature is restricted as an unified value, i.e., the lower value between $T_{\text {crit }}-3{ }^{\circ} \mathrm{C}$ and $T_{8}-\Delta T_{\mathrm{pp}, \mathrm{e}}$. The overheating degree is equal to be zero for the saturated cycle, and the maximum overheating degree is the lower value between $30^{\circ} \mathrm{C}$ and $T_{8}-\Delta T_{\mathrm{pp}, \mathrm{e}}-T_{\mathrm{ev}}$ (the temperature difference between maximum turbine inlet temperature and evaporating temperature).

\section{Results and Discussions}

A typical superheated non-regenerative ORC system using R236fa and R245ca in [27] is selected to validate the previous mentioned mathematical modelling in Section 2. The thermodynamic properties of working fluids R236fa and R245ca are also obtained from NIST REFPROP database. The mass flow rate, net power output and part of working states are calculated and compared, and shown in Table 3 . The relative error of net power output is respectively $1.04 \%$ lower than the reference results for R236fa and $0.85 \%$ lower for R245ca. Therefore, the present calculated results show very good agreement.

Table 3. Validation of present mathematical modeling.

\begin{tabular}{ccccccc}
\hline Parameter & $\begin{array}{c}\text { Reference } \\
\text { Result }\end{array}$ & $\begin{array}{c}\text { Present } \\
\text { Result }\end{array}$ & Error (\%) & $\begin{array}{c}\text { Reference } \\
\text { Result }\end{array}$ & $\begin{array}{c}\text { Present } \\
\text { Result }\end{array}$ & Error (\%) \\
\hline Fluid & & R236fa & & & R245ca & \\
\hline$p_{1}(\mathrm{kPa})$ & 1700.00 & 1700.00 & 0.00 & 700.00 & 700.00 & 0.00 \\
$T_{1}(\mathrm{~K})$ & 367.95 & 367.95 & 0.00 & 363.55 & 363.50 & -0.01 \\
$T_{2}(\mathrm{~K})$ & 330.15 & 329.16 & -0.30 & 334.35 & 331.73 & -0.78 \\
$T_{5}(\mathrm{~K})$ & 318.05 & 317.75 & -0.09 & 317.55 & 317.39 & -0.05 \\
$T_{9}(\mathrm{~K})$ & 350.15 & 348.58 & -0.45 & 354.45 & 355.01 & 0.16 \\
$m_{\mathrm{wf}}(\mathrm{kg} / \mathrm{s})$ & 23.07 & 23.56 & 2.12 & 14.88 & 15.12 & 1.61 \\
$W_{\text {net }}(\mathrm{kW})$ & 335.23 & 331.73 & -1.04 & 303.15 & 300.56 & -0.85 \\
\hline
\end{tabular}

In the following Sections 4.1 and 4.2, the geothermal brine with a mass flow rate of $10 \mathrm{~kg} / \mathrm{s}$ and a temperature of $150^{\circ} \mathrm{C}$ is used to illustrate the effect of reinjection temperature limit. The influences of geothermal brine mass flow rate and temperature are given in Section 4.3.

\subsection{Without Reinjection Temperature Limit}

Take working fluid R245fa for example, comparison between the saturated and superheated non-regenerative cycles are performed and illustrated. The turbine inlet overheating degree varies from $0^{\circ} \mathrm{C}$ to $30^{\circ} \mathrm{C}$. Figure 4 shows the turbine efficiency variation with different turbine inlet overheating degree at three evaporating temperature $T_{\mathrm{ev}}=70^{\circ} \mathrm{C}, 90^{\circ} \mathrm{C}$ and $110^{\circ} \mathrm{C}$. With the increasing of turbine inlet overheating degree, $V R$ and $S P$ both decreases, but turbine efficiency $\eta_{\mathrm{t}}$ slightly increases at each fixed evaporating temperature. For example, at $T_{\mathrm{ev}}=90^{\circ} \mathrm{C}$, superheated vapor with $\Delta T_{1, \mathrm{oh}}=30^{\circ} \mathrm{C}$ yields a turbine efficiency with the value of $87.21 \%$, and saturated vapor gives a turbine efficiency with the value of $87.17 \%$. The improvement of turbine efficiency due to the change of turbine inlet and outlet conditions is only $0.05 \%$. Comparatively, the variation of turbine efficiency is sensitive to the the evaporating temperature with a difference of about $2.5 \%$ at evaporating temperature of $70{ }^{\circ} \mathrm{C}$ to $110^{\circ} \mathrm{C}$.

The change of plant exergy efficiency $\eta$ versus turbine inlet overheating degree $\Delta T_{1 \text {,oh }}$ at three evaporating temperatures $T_{\mathrm{ev}}=70{ }^{\circ} \mathrm{C}, 90^{\circ} \mathrm{C}$ and $110{ }^{\circ} \mathrm{C}$ are shown in Figure 5. It can be clearly seen that the plant exergy efficiency decreases with the increasing of overheating degree at the turbine inlet, and the saturated vapor gives the maximum plant exergy efficiency at each evporating temperature. This conclusion is consistent with the previous findings [11-13] for ORC systems with a fixed turbine efficiency. Recall the variation of turbine efficiency is very small, and thus has limited impact on superiority of the saturated cycle. Thus, if there is no constraint on the reinjection temperature, the optimal cycle configuration is the saturated non-regenerative cycle. Besides, the saturated vapor at different evaporating temperature yield different plant exergy efficiency, as shown in Figure 5. 


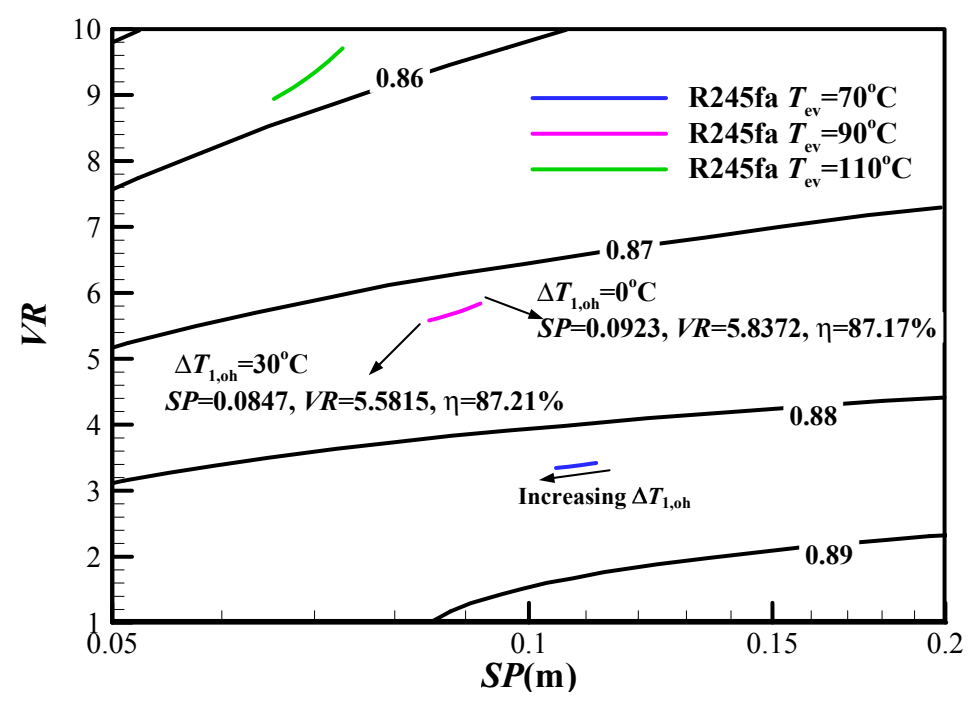

Figure 4. Variation of turbine efficiency versus overheating degree.

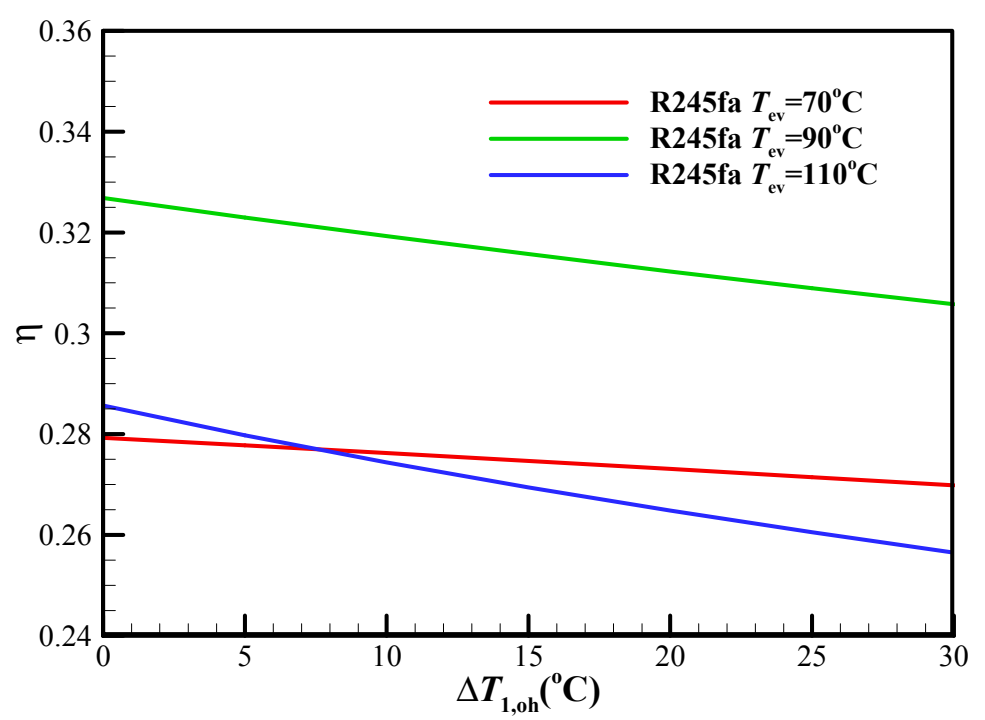

Figure 5. Variation of plant exergy efficiency versus overheating degree.

The variations of plant exergy efficiency $\eta$ and the reinjection temperature $T_{9}$ versus evaporating temperature $T_{\mathrm{ev}}$ for saturated non-regenerative cycle using R245fa and isobutane are shown in Figure 6. It is obvious that the shapes of the plant exergy efficiency curve are both somewhat parabolic with local maximum values. By using isobutane, the evaporating temperature higher than $127.2^{\circ} \mathrm{C}$ doesn't work due to the limitation of minimum dryness fraction in expansion process. The maximum plant exergy efficiency is $32.70 \%$ at evaporating temperature of $91.40{ }^{\circ} \mathrm{C}$ for $\mathrm{R} 245 \mathrm{fa}$, and $33.71 \%$ at evaporating temperature of $94.07^{\circ} \mathrm{C}$ for isobutane. Besides, the reinjection temperature increases with the increasing of evaporating temperature for both working fluid, which is accordance with the conclusion based on the theoretical analysis in Section 2. The optimal reinjection temperatures at optimal working condition are respectively $71.56{ }^{\circ} \mathrm{C}$ for $\mathrm{R} 245 \mathrm{fa}$, and $68.34{ }^{\circ} \mathrm{C}$ for isobutane.

Table 4 listed the optimal working conditions and part of main system performances for all four working fluids without reinjection temperature limit. It can be seen that the evaporating temperatures for all working fluids are around $90^{\circ} \mathrm{C}$, and reinjection temperatures vary mildly from $68.39^{\circ} \mathrm{C}$ for isobutane to $74.02{ }^{\circ} \mathrm{C}$ for $\mathrm{R} 1234 \mathrm{ze}(\mathrm{Z})$. The mass flow rates for R245fa and $\mathrm{R} 1234 \mathrm{ze}(\mathrm{Z})$ are quite larger than these for isopentane and isobutane due to their lower latent enthalpies, which are shown in Table 2. This can be also explained base on Equation (1). The values of turbine efficiency are around 
$87 \%$ with maximum variation of $0.36 \%$ only. As shown in Figure 7 , the optimal working conditions for the single stage radial inflow turbine are all plotted in the turbine efficiency map. The highest optimal turbine efficiency is achieved for $\mathrm{R} 1234 \mathrm{ze}(\mathrm{Z})$ which shows the highest size parameter and a moderate volumetric expansion ratio. The plant exergy efficiencies vary from $31.89 \%$ for isopentane to $33.71 \%$ for isobutane. The saturated non-regenerative cycles using R245fa and R1234ze(Z) show moderate plant exergy efficiencies.

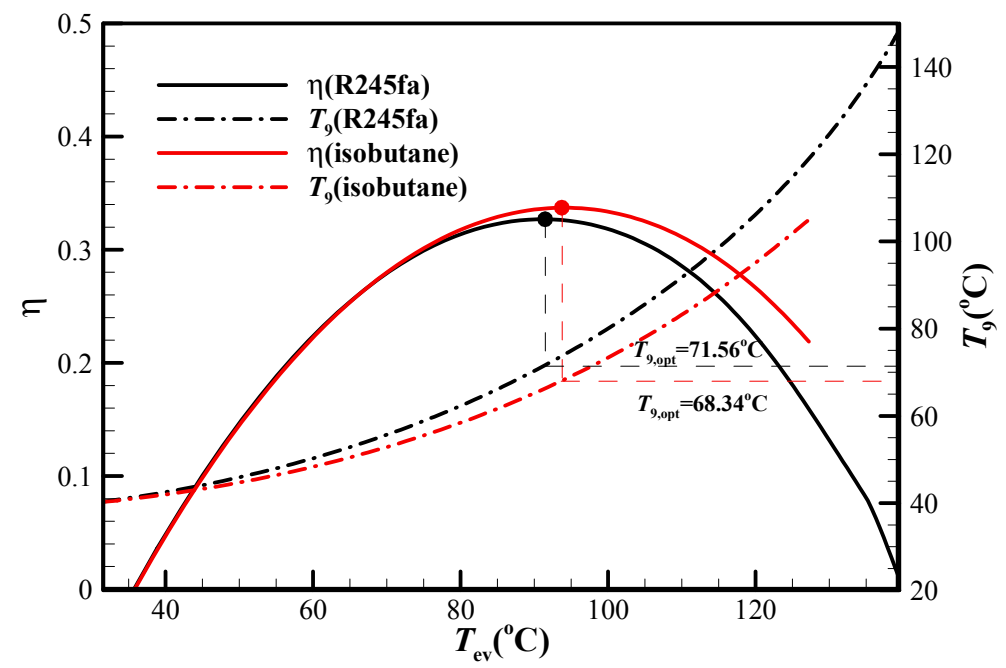

Figure 6. Plant exergy efficiency, reinjection temperature versus evaporating temperature.

Table 4. Optimal working condition and performance without reinjection temperature limit.

\begin{tabular}{cccccc}
\hline Working Fluid & $\boldsymbol{T}_{\text {ev,opt }}\left({ }^{\circ} \mathbf{C}\right)$ & $\boldsymbol{T}_{\mathbf{9 , 0 p t}}\left({ }^{\circ} \mathbf{C}\right)$ & $\boldsymbol{m}_{\mathbf{w f}, \mathbf{o p t}}(\mathbf{k g} / \mathbf{s})$ & $\boldsymbol{\eta}_{\mathrm{t}, \mathbf{o p t}}(\mathbf{\%})$ & $\boldsymbol{\eta}_{\mathbf{o p t}}(\mathbf{\%})$ \\
\hline $\mathrm{R} 245 \mathrm{fa}$ & 91.40 & 71.56 & 14.47 & 87.08 & 32.70 \\
R1234ze $(Z)$ & 90.95 & 73.84 & 13.54 & 87.28 & 32.13 \\
isopentane & 89.44 & 73.35 & 7.49 & 87.44 & 31.89 \\
isobutane & 94.07 & 68.34 & 8.70 & 87.22 & 33.71 \\
\hline
\end{tabular}

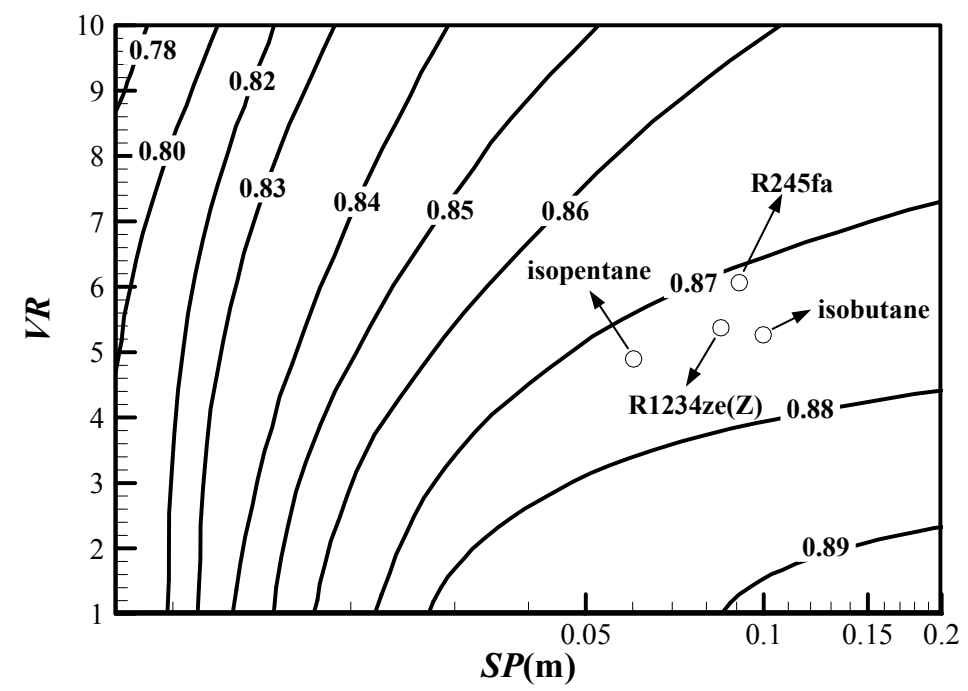

Figure 7. Variation of turbine efficiency with $S P$ and $V R$ at optimal working condition. 


\subsection{Considering Reinjection Temperature Limit}

When the reinjection temperature limit is imposed, the plant exergy efficiency versus evaporating temperature map is limited by an isoline of reinjection temperature limit. Hence, the performance line with constant reinjection temperature limit should be obtained in advance.

Figures 8 and 9 show the curves of plant exergy efficiency $\eta$ versus evaporating temperature $T_{\mathrm{ev}}$ along the three reinjection temperature limit isolines $\left(T_{9, \mathrm{lim}}=70^{\circ} \mathrm{C}, 75^{\circ} \mathrm{C}, 85^{\circ} \mathrm{C}\right) \mathrm{using} \mathrm{R} 245 \mathrm{fa}$ and isobutane for the non-regenerative and regenerative cycles. The plant exergy efficiency curve for the saturated cycle and for the superheated cycles with constant overheating degrees $\Delta T_{1, \mathrm{oh}}=10^{\circ} \mathrm{C}$, $20{ }^{\circ} \mathrm{C}$ and $30^{\circ} \mathrm{C}$ are also plotted. Furthermore, the optimal working condition without reinjection temperature limit is shown for comparison. As shown in Figures 8 and 9 , the plant exergy efficiency curve with a constant reinjection temperature limit can be treated as a left margin, and the plant exergy efficiency curves with constant overheating degrees of $0{ }^{\circ} \mathrm{C}$ and $30{ }^{\circ} \mathrm{C}$ can be treated as the top and bottom borders. The difference between the non-regenerative and regenerative cycles is the left margins with different shape and location. The plant exergy efficiency curve for the regenerative cycle is shifted to the left side of that for non-regenerative cycle. Moreover, the plant exergy efficiency curve for the regenerative cycle covers a wide range of evaporating temperature, which means a wider available operating range.

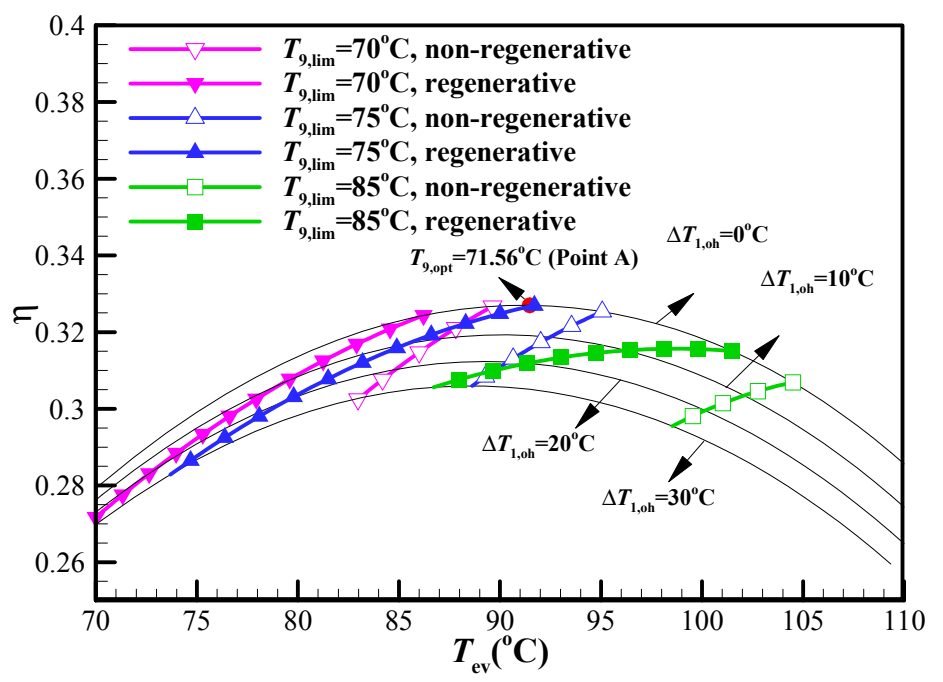

Figure 8. Plant exergy efficiency profiles with various reinjection temperature limits using R245fa.

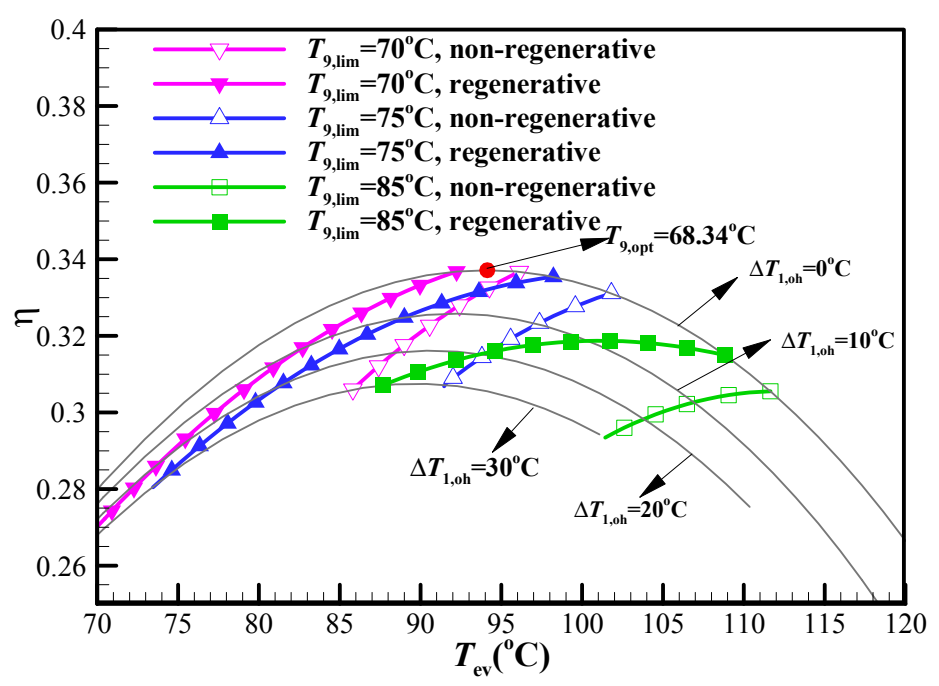

Figure 9. Plant exergy efficiency profiles with various reinjection temperature limits using isobutane. 
For illustrative purposes, three points A, B and C are also plotted in Figures 8 and 9. Point A is labeled at the optimal point without reinjection temperature limit, points $B$ and $C$ are the intersection point between saturated line and constant reinjection temperature line for non-regenerative cycle and regenerative cycle respectively. It is obvious that point $C$ is always on the left side of point $B$ due to the heat recovery by regenerator. When point $B\left(T_{9, \lim }=70^{\circ} \mathrm{C}\right.$ for $\left.\mathrm{R} 245 \mathrm{fa}\right)$ is located on the left side of point $A$, i.e., the reinjection temperature at point $B$ is lower than the optimal reinjection temperature, the optimal working condition stays at point $A$ and the optimal cycle configuration is the saturated non-regenerative cycle. When point $A$ is located between point $C$ and point $B\left(T_{9, \text { lim }}=70{ }^{\circ} \mathrm{C}\right.$ for isobutane), the optimal cycle configuration is the saturated regenerative cycle. The optimal working condition for this case has the same plant exergy efficiency and evaporating temperature as point $A$, but different reinjection temperature. When point $B$ and point $C$ are both located on the right side of point $\mathrm{A}\left(T_{9, \mathrm{lim}}=75^{\circ} \mathrm{C}, 85^{\circ} \mathrm{C}\right.$ for R245fa, isobutane), the optimal working condition must lies on the reinjcetion temperature limit line. The optimal cycle configuration is, whether the saturated or superheated regenerative cycle, depends on the plant exergy efficiency curve with constant reinjcetion temperature limit. The profiles of plant exergy efficiency versus overheating degree on the isolines of $T_{9, \lim }=75^{\circ} \mathrm{C}, 85^{\circ} \mathrm{C}$ are shown in Figure 10. It can be seen that highest plant exergy efficiency is achieved at saturated state (point $\mathrm{C}$ ) when $T_{9, \lim }=75{ }^{\circ} \mathrm{C}$ for either working fluid. The highest exergy efficiencies are obtained respectively at superheated states (point $\mathrm{D}$ shown in Figure 10) with $\Delta T_{1, \mathrm{oh}}=4.65^{\circ} \mathrm{C}$ for R245fa and with $\Delta T_{1, \mathrm{oh}}=9.24^{\circ} \mathrm{C}$ for isobutane when $T_{9, \mathrm{lim}}=85^{\circ} \mathrm{C}$.

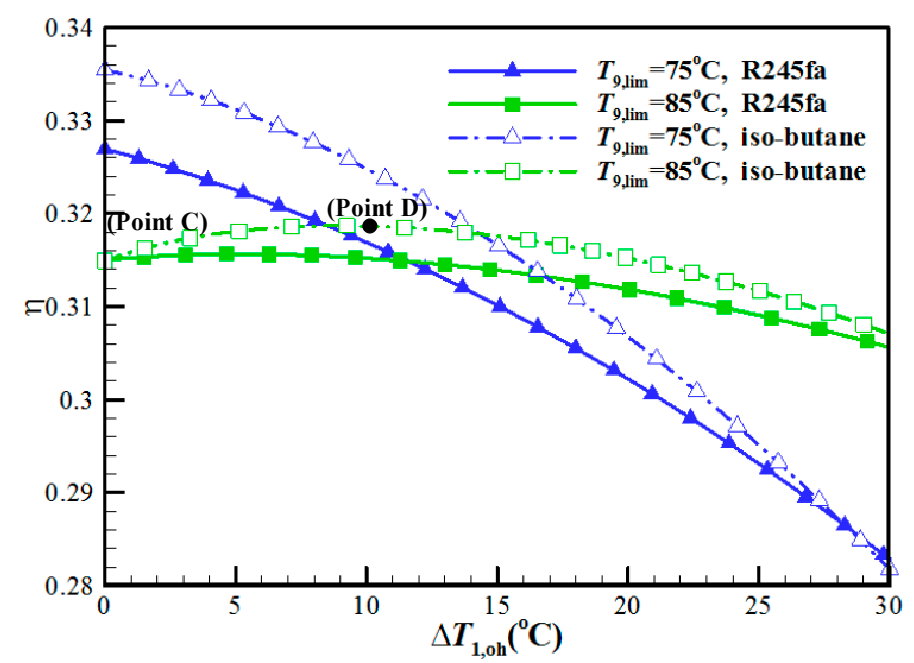

Figure 10. Plant exergy efficiency versus overheating degree with reinjection temperance limit.

Based on the above analysis, a new optimization approach for selecting optimal subcriticial cycle configuration and obtaining optimal working condition are proposed considering the influence of reinjection temperature limit. The step-by-step optimization process is illustrated in Figure 11. The first cycle configuration investigated is the saturated non-regenerative cycle. The only design variable is the evaporating temperature, and the optimal point $\mathrm{A}\left(T_{\mathrm{ev}, \mathrm{opt}}, \eta_{\mathrm{opt}}, T_{9, \mathrm{opt}}\right)$ can be obtained along the saturated performance line as shown in Figure 6. Then the relationship between the optimal reinjection temperature at point $A$ and the given reinjection temperature limit is needed to be estimated. If $T_{9, \text { lim }}$ is equal to or less than $T_{9, \mathrm{opt}}$, the saturated non-regenerative cycle is the optimal cycle configuration and the optimal working point is point $A$. If $T_{9, \text { lim }}$ is higher than $T_{9, \mathrm{opt}}$, the second cycle configuration, i.e., saturated regenerative cycle, is needed to be studied, and point $C\left(T_{\text {ev,lim }}, \eta_{\text {lim }}, T_{9, \text { lim }}\right)$ can be obtained with given reinjection temperature limit. Then, a comparison between point $C$ and point $A$ is carried out. If $T_{\text {ev,lim }}$ is equal to or less than $T_{\text {ev,opt }}$, the optimal cycle configuration is the saturated regenerative cycle, and the optimal evaporating temperature and the plant exergy efficiency are equal to those at point $\mathrm{A}$, but the reinjection temperature should be calculated for the saturated regenerative 
cycle. If $T_{\text {ev,lim }}$ is higher than $T_{\text {ev,opt }}$, the third cycle configuration, i.e., superheated regenerative cycle, is needed to be investigated along the given reinjection temperature isoline. Here two design variables including evaporating temperature and overheating degree are needed to be optimized to get the working point $\mathrm{D}\left(T_{\mathrm{ev}, \max }, \eta_{\max }, \Delta T_{1, \mathrm{oh}}, T_{9, \text { lim }}\right)$ with local maximum plant exergy efficiency along the given reinjection temperature line. Then, the relationship between $\eta_{\max }$ and $\eta_{\text {lim }}$ is compared. If $\eta_{\max }$ is less than $\eta_{\text {lim }}$, the saturated regenerative cycle is the optimal cycle configuration, and point $C$ is the optimal working point. Otherwise, the optimal cycle configuration is the superheated regenerative cycle, and point $\mathrm{D}$ is the optimal working condition.

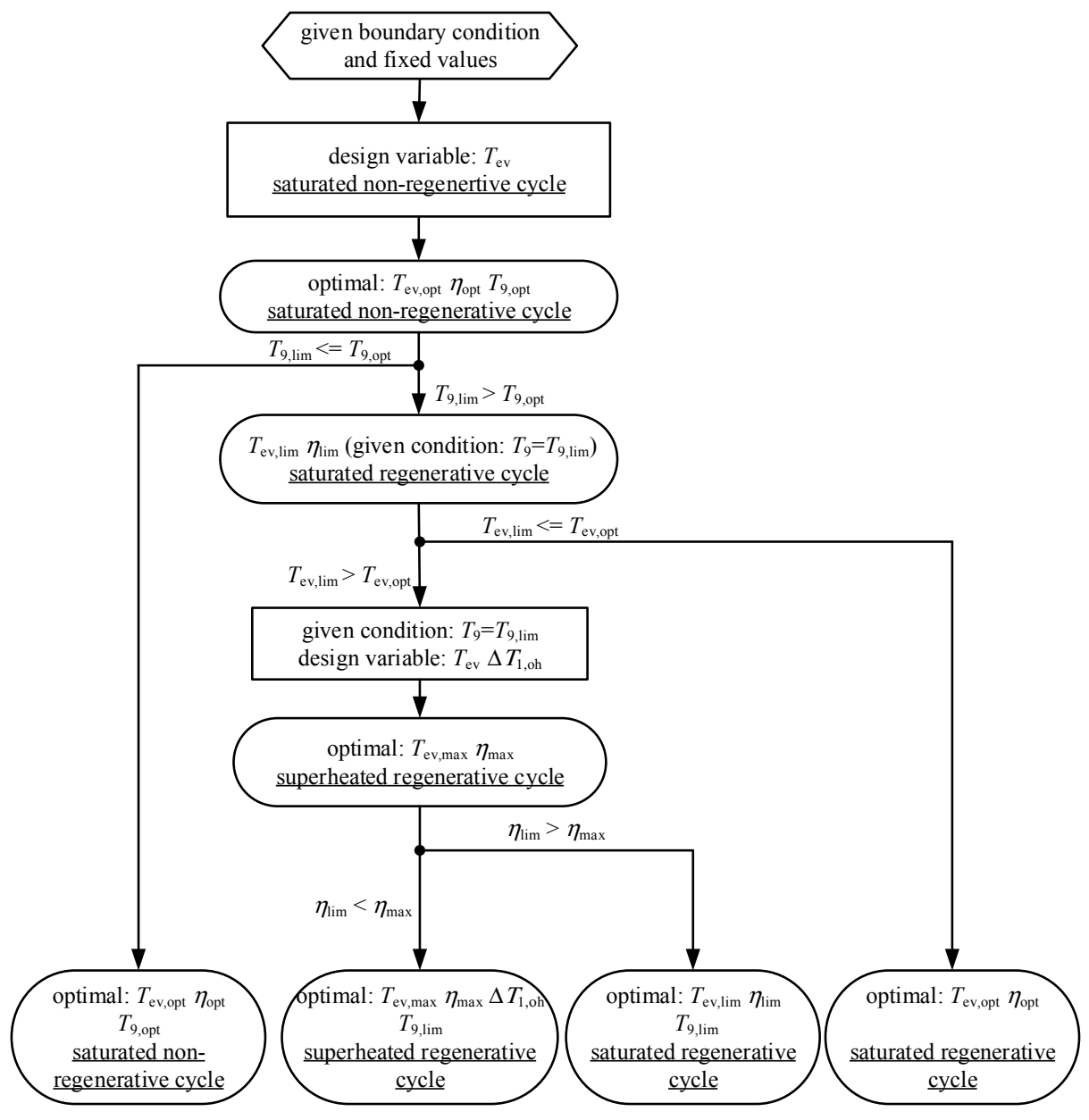

Figure 11. New optimization process.

The proposed new optimization approach can be applied to complete the selection of optimal cycle configuration with up to three judgments on the reinjection temperature and the evaporating temperature, and up to two optimization calculations along the saturated line and along the given reinjection temperature line. Through this approach, most of unnecessary working conditions can be eliminated, which can significantly increase the optimization efficiency and save the optimization time.

\subsection{Optimal Results}

The optimal cycle configuration, the optimal plant exergy efficiency, and the relevant optimal working condition with three different reinjection temperature limits are listed in Table 5. Abbreviations sta-non (saturated non-regenerative), sta-reg (saturated regenerative), and sup-reg (superheated regenerative) are used for convenience here. According to Table 5, the optimal cycle configurations are saturated non-regenerative cycles with the lowest reinjection temperature limit $T_{9, \text { lim }}=70^{\circ} \mathrm{C}$ using working fluids R245fa, R1234ze(Z) and isopentane. Due to $T_{9, \text { opt }}$ shown in Table 4 are higher than 
$70{ }^{\circ} \mathrm{C}$, the optimal evaporating temperatures and the plant exergy efficiencies are all kept unchanged using the above three working fluids. But the optimal cycle configuration using isobutane with $T_{9, \lim }=70{ }^{\circ} \mathrm{C}$ is a saturated regenerative cycle. In spite of the optimal evaporating and the plant exergy efficiency using isobutane are kept unchanged, but the reinjection temperature is higher (with value of $71.54{ }^{\circ} \mathrm{C}$ ) than the reinjection temperature limit. When the reinjection temperature limit increases to $75^{\circ} \mathrm{C}$, the optimal cycle configurations change to saturated regenerative cycles for all four working fluids. Noted that the reinjection temperature using R245fa, R1234ze(Z) and isobutane are all equal to $75^{\circ} \mathrm{C}$, but higher using isopentane. Furthmore, the optimal evpaoration temperatures with $T_{9, \text { lim }}=70^{\circ} \mathrm{C}$ and $75^{\circ} \mathrm{C}$ are the same using isopentane. With further increasing of reinjection temperature limit, the optimal cycle configurations are all superheated regenerative cycles except for the case using isopentane. With the increasing of the reinjection temperature limit, the optimal evaporating temperature increases, the mass flow rate of working fluid, the turbine efficiency and the optimal plant exergy efficiency decrease for all the working fluids. Combining with the conclusion obtained from Table 4, isobutane always has the highest plant exergy efficiency without and with reinjection temperature limit.

Table 5. Optimal cycle configuration and performances $\left(m_{\mathrm{hf}}=10 \mathrm{~kg} / \mathrm{s}, \mathrm{T}_{8}=150{ }^{\circ} \mathrm{C}\right)$.

\begin{tabular}{ccccccccc}
\hline Working Fluid & $\boldsymbol{T}_{\mathbf{9}, \text { lim }}\left({ }^{\circ} \mathbf{C}\right)$ & Optimal Cycle & $T_{\text {ev }}\left({ }^{\circ} \mathbf{C}\right)$ & $\Delta \boldsymbol{T}_{\mathbf{1 , 0 h}}\left({ }^{\circ} \mathbf{C}\right)$ & $\boldsymbol{T}_{\mathbf{9}}\left({ }^{\circ} \mathbf{C}\right)$ & $\left.\boldsymbol{m}_{\mathbf{w f}} \mathbf{( k g} / \mathbf{s}\right)$ & $\eta_{\mathbf{t}}(\%)$ & $\eta(\%)$ \\
\hline \multirow{3}{*}{ R245fa } & 70 & sta-non & 91.40 & 0 & 71.56 & 14.47 & 87.08 & 32.698 \\
& 75 & sta-reg & 91.71 & 0 & 75 & 14.43 & 87.06 & 32.696 \\
& 85 & sup-reg & 98.96 & 4.65 & 85 & 12.34 & 86.62 & 31.57 \\
\hline \multirow{3}{*}{ R1234ze(Z) } & 70 & sta-non & 90.95 & 0 & 73.84 & 13.54 & 87.28 & 32.13 \\
& 75 & sta-reg & 91.82 & 0 & 75 & 13.38 & 87.23 & 32.12 \\
& 85 & sup-reg & 94.70 & 14.44 & 85 & 11.44 & 87.08 & 31.29 \\
\hline \multirow{3}{*}{ isopentane } & 70 & sta-non & 89.44 & 0 & 73.35 & 7.49 & 87.44 & 31.89 \\
& 75 & sta-reg & 89.44 & 0 & 78.83 & 7.49 & 87.44 & 31.89 \\
& 85 & sta-reg & 95.33 & 0 & 85 & 6.78 & 87.11 & 31.50 \\
\hline \multirow{3}{*}{ isobutane } & 70 & sta-reg & 94.13 & 0 & 71.54 & 8.69 & 87.21 & 33.71 \\
& 75 & sta-reg & 98.22 & 0 & 75 & 8.27 & 86.93 & 33.54 \\
& 85 & sup-reg & 100.93 & 9.24 & 85 & 7.08 & 86.79 & 31.87 \\
\hline
\end{tabular}

Compared with the optimal results in Table 5, two other optimal results obtained with a higher brine mass flow rate $m_{\mathrm{hf}}=20 \mathrm{~kg} / \mathrm{s}$ and a lower brine temperature $T_{8}=130{ }^{\circ} \mathrm{C}$ are respectively given in Tables 6 and 7. It can be seen that the optimal cycle configurations under different mass flow rate of geothermal brine for each reinjection temperature limit do not alter, and increasing the mass flow rate of geothermal brine has limited effect on the optimal evaporating temperature, inlet overheating temperature, reinjection temperature. The turbine efficiency has an increase of about $0.1 \%$ for isopentane working fluid to $0.3 \%$ for isobutane working fluid under $m_{\mathrm{hf}}=20 \mathrm{~kg} / \mathrm{s}$ due to the higher $S P$ and near equal $V R$, thus the plant exergy efficiency increases by about $0.15 \%$ with isopentane working fluid to $0.3 \%$ for isobutane working fluid. This conclusion about turbine efficiency and plant exergy efficiency caused by the heat source mass flow rate is consistent with that in [24]. For a geothermal brine heat source with a lower temperature $T_{8}=130{ }^{\circ} \mathrm{C}$, the optimal cycle configuration is kept as the same except for working fluid R1234ze(Z) with $T_{9 . \lim }=85^{\circ} \mathrm{C}$. Due to the lower brine temperature, the optimal evaporating temperature, the mass flow rate of working fluid, and the plant exergy all decrease. Besides, the optimal overheating degree at the inlet is much higher under $T_{8}=130{ }^{\circ} \mathrm{C}$ than that under $T_{8}=130{ }^{\circ} \mathrm{C}$ with $T_{9, \text { lim }}=85^{\circ} \mathrm{C}$, which means that a higher reinjection temperature limit yiled a higher superheated vapor at turbine inlet under a lower geothermal brine temperature with a maximum plant exergy efficiency. From the data in Tables 6 and 7, isobutane working fluid also shows highest plant exergy efficiency than other working fluids. This means that the optimal working fluid is independent of the reinjection temperature for the studied cases (with different geothermal brine temperature and mass flow rate) in the present work. 
Table 6. Optimal cycle configuration and performances $\left(m_{\mathrm{hf}}=20 \mathrm{~kg} / \mathrm{s}, \mathrm{T}_{8}=150{ }^{\circ} \mathrm{C}\right)$.

\begin{tabular}{ccccccccc}
\hline Working Fluid & $\boldsymbol{T}_{\mathbf{9}, \text { lim }}\left({ }^{\circ} \mathbf{C}\right)$ & Optimal Cycle & $\boldsymbol{T}_{\mathbf{e v}}\left({ }^{\circ} \mathbf{C}\right)$ & $\Delta \boldsymbol{T}_{\mathbf{1 , o h}}\left({ }^{\circ} \mathbf{C}\right)$ & $\boldsymbol{T}_{\mathbf{9}}\left({ }^{\circ} \mathbf{C}\right)$ & $\boldsymbol{m}_{\mathbf{w f}} \mathbf{( k g / s )}$ & $\eta_{\mathbf{t}}(\mathbf{\%})$ & $\eta(\mathbf{\%})$ \\
\hline \multirow{3}{*}{ R245fa } & 70 & sta-non & 91.40 & 0 & 71.56 & 28.98 & 87.24 & 32.899 \\
& 75 & sta-reg & 91.73 & 0 & 75 & 28.86 & 87.23 & 32.898 \\
& 85 & sup-reg & 99.34 & 4.01 & 85 & 24.66 & 86.87 & 31.80 \\
\hline \multirow{3}{*}{ R1234ze(Z) } & 70 & sta-non & 91.15 & 0 & 74.01 & 27.01 & 87.43 & 32.323 \\
& 75 & sta-reg & 91.84 & 0 & 75 & 26.76 & 87.39 & 32.322 \\
& 85 & sup-reg & 94.74 & 14.42 & 85 & 22.87 & 87.28 & 31.49 \\
\hline \multirow{3}{*}{ isopentane } & 70 & sta-non & 89.55 & 0 & 73.46 & 14.96 & 87.53 & 32.04 \\
& 75 & sta-reg & 89.55 & 0 & 79.01 & 14.96 & 87.53 & 32.04 \\
& 85 & sta-reg & 95.35 & 0 & 85 & 13.56 & 87.26 & 31.67 \\
\hline \multirow{3}{*}{ isobutane } & 70 & sta-reg & 94.31 & 0 & 71.65 & 17.35 & 87.47 & 34.01 \\
& 75 & sta-reg & 98.26 & 0 & 75 & 16.52 & 87.24 & 33.85 \\
& 85 & sup-reg & 100.65 & 9.68 & 85 & 14.16 & 87.15 & 32.17 \\
\hline
\end{tabular}

Table 7. Optimal cycle configuration and performances $\left(m_{\mathrm{hf}}=10 \mathrm{~kg} / \mathrm{s}, T_{8}=130^{\circ} \mathrm{C}\right)$.

\begin{tabular}{ccccccccc}
\hline Working Fluid & $\boldsymbol{T}_{\mathbf{9}, \text { lim }}\left({ }^{\circ} \mathbf{C}\right)$ & Optimal Cycle & $\boldsymbol{T}_{\mathbf{e v}}\left({ }^{\circ} \mathbf{C}\right)$ & $\Delta \boldsymbol{T}_{\mathbf{1 , 0 h}}\left({ }^{\circ} \mathbf{C}\right)$ & $\boldsymbol{T}_{\mathbf{9}}\left({ }^{\circ} \mathbf{C}\right)$ & $\boldsymbol{m}_{\mathbf{w f}}(\mathbf{k g} / \mathbf{s})$ & $\eta_{\mathbf{t}}(\mathbf{\%})$ & $\boldsymbol{\eta}(\mathbf{\%})$ \\
\hline \multirow{3}{*}{ R245fa } & 70 & sta-non & 79.15 & 0 & 70.81 & 11.27 & 87.73 & 27.98 \\
& 75 & sta-reg & 81.68 & 0 & 75 & 10.72 & 87.57 & 27.89 \\
& 85 & sup-reg & 83.94 & 23.18 & 85 & 8.63 & 87.44 & 26.45 \\
\hline \multirow{3}{*}{ R1234ze(Z) } & 70 & sta-non & 79.00 & 0 & 72.43 & 10.46 & 87.89 & 27.54 \\
& 75 & sup-reg & 80.42 & 3.23 & 75 & 9.94 & 87.81 & 27.46 \\
& 85 & sup-reg & 82.71 & 30 & 85 & 7.99 & 87.69 & 26.61 \\
\hline \multirow{3}{*}{ isopentane } & 70 & sta-non & 78.54 & 0 & 72.05 & 5.87 & 87.96 & 27.61 \\
& 75 & sta-reg & 78.54 & 0 & 75.22 & 5.87 & 87.96 & 27.61 \\
& 85 & sup-reg & 87.25 & 1.32 & 85 & 4.74 & 87.44 & 26.33 \\
\hline \multirow{3}{*}{ isobutane } & 70 & sta-reg & 80.22 & 0 & 70.95 & 6.67 & 87.88 & 28.27 \\
& 75 & sta-reg & 84.33 & 0 & 75 & 6.17 & 87.61 & 28.01 \\
& 85 & sup-reg & 84.80 & 23.01 & 85 & 4.97 & 87.59 & 26.38 \\
\hline
\end{tabular}

\section{Conclusions}

A new optimization approach was proposed to select the optimal subcritical cycle configuration with the maximum plant exergy efficiency based on the theoretical and typical case analysis among saturated/superheated, non-regenerative/regenerative cycles, especially with the consideration of the reinjection temperature limit. The following conclusions were drawn from the results of the current work:

(1) A saturated non-regenerative cycle, saturated regenerative cycle, and superheated regenerative cycle are the most possible optimal cycle configurations. The optimal cycle configuration and the relevant working condition strongly depend on the value of reinjection temperature limit.

(2) When the reinjection temperature limit exhibits influence on the system performance, the optimal plant exergy efficiency normally decreases with the increasing of reinjection temperature limit.

(3) In the considered cases, with the assumed contains and hypothesis, working fluid isobutane always shows a higher plant exergy efficiency than other three working fluids without and with reinjection temperature limit.

Author Contributions: Formal analysis, J.F.; Methodology, C.Z.; Software, C.Z.; Supervision, J.L.; Visualization, P.Y.

Funding: This research was funded by National Natural Science Foundation of China (grant number 51776201) and Tianjin Science \& Technology Pillar Program (grant number 17YFZCSF01240).

Conflicts of Interest: The authors declare no conflict of interest. 


\section{Abbreviations}

$\begin{array}{ll}\text { Abbreviations } & \\ \text { ORC } & \text { Organic Rankine Cycle } \\ \text { GWP } & \text { Global warming potential } \\ \text { sta-non } & \text { Saturated non-regenerative } \\ \text { sta-reg } & \text { Saturated non-regenerative } \\ \text { sup-reg } & \text { Superheated regenerative }\end{array}$

Nomenclature

$c_{\mathrm{p}}$

Specific heat capacity at constant pressure $(\mathrm{J} /(\mathrm{kg} \cdot \mathrm{K}))$

$m \quad$ Mass flow rate $(\mathrm{kg} / \mathrm{s})$

$p \quad$ Pressure $(\mathrm{kPa})$

$\mathrm{s} \quad$ Specific entropy $(\mathrm{J} /(\mathrm{kg} \cdot \mathrm{K}))$

SP Turbine size parameter $(\mathrm{m})$

$T \quad$ Temperature $\left({ }^{\circ} \mathrm{C}\right)$

$V \quad$ Volumetric flow rate $\left(\mathrm{m}^{3} / \mathrm{s}\right)$

$V R \quad$ Volumetric expansion ratio (-)

W Power (W)

\section{Subscripts}

Ambient condition

Turbine inlet

Turbine outlet

Regenerator outlet at low pressure

Turbine outlet with isentropic expansion

Saturated vapor state in condenser

Relevant point for cooling fluid in condenser at pinch point

Feed pump inlet

Feed ump outlet

Regenerator outlet at high pressure

Feed pump outlet with isentropic compression

Saturated liquid state in evaporator

Relevant point for hot fluid in evaporator at beginning

evpaoration point

Saturated vapor state in evaporator

Hot fluid inlet

Hot fluid outlet

Cold fluid inlet

Cold fluid outlet

Condenser

cf Cold fluid

cond Condensing state

crit Critical point

e Evaporator

ev Evaporating

hf Hot fluid

g Generator

lim Reinjetion temperature limit

m Transmission device

$\max \quad$ Maximum value

$\min \quad$ Minimum value

motor motor for feed pump or circulating pump

net net power output

opt Optimal condition without reinjection temperature limit

$\mathrm{p} \quad$ Feed pump

pc Circulating pump

pp Pinch point

r Regenerator

sta Saturated state

sym System 


$\begin{array}{ll}\mathrm{t} & \text { Turbine } \\ \mathrm{wf} & \text { Working fluid } \\ \text { Greek symbols } & \\ \eta & \text { Efficiency }(-) \\ \Delta h & \text { Latent enthalpy }(\mathrm{J} / \mathrm{kg}) \\ \Delta T_{1, \mathrm{oh}} & \text { Overheating degree at turbine inlet }\left({ }^{\circ} \mathrm{C}\right) \\ \Delta T_{\mathrm{pp}} & \text { Pinch point temperature difference }\left({ }^{\circ} \mathrm{C}\right)\end{array}$

\section{References}

1. Zarrouk, S.J.; Moon, H. Efficiency of geothermal power plants: A world review. Geothermics 2014, 51, $142-153$. [CrossRef]

2. Astofli, M.; Xodo, I.; Romano, M.C.; Macchi, E. Technical and economical analysis of a solar-geothermal hybrid plant based on an organic Rankine cycle. Geothermics 2011, 40, 58-68. [CrossRef]

3. Tchanche, B.F.; Lambrinos, G.; Frangoudakis, A.; Papadakis, G. Low-grade heat conversion into power using organic Rankine cycles-A review of various applications. Renew. Sustain. Energy Rev. 2011, 15, 3963-3979. [CrossRef]

4. Vignesh, P.; Suresh, S.; Grashin, C.J. Issues, comparsions, turbine selections and applications-An overview in organic Rankine cycle. Energy Convers. Manag. 2018, 166, 474-488. [CrossRef]

5. Manente, G.; Lazzaretto, A.; Bonamico, E. Design guidelines for the choice between single and dual pressure layouts in organic Rankine cycle (ORC) systems. Energy 2017, 123, 413-431. [CrossRef]

6. Li, T.L.; Hu, X.X.; Wang, J.Q.; Kong, X.F.; Liu, J.; Zhu, J.L. Performance improvement of two-stage serial organic Rankine cycle (TSORC) driven by dual-level heat sources of geothermal energy coupled with solar energy. Geothermics 2018, 76, 261-270. [CrossRef]

7. Yari, M. Exergetic analysis of various types of geothermal power plants. Renew. Energy 2010, 35, $112-121$. [CrossRef]

8. Astolfi, M.; Diega, L.N.; Romano, M.C.; Merlo, U.; Filippini, S.; Macchi, E. Application of the novel "Emeritus" air cooled condenser in geothermal ORC. Energy Procedia 2017, 129, 479-486. [CrossRef]

9. Maraver, D.; Royo, J.; Lemort, V.; Quoilin, S. Systematic optimization of subcritical and transcritical organic Rankine cyles (ORCs) constrained by technical parameters in multiple applications. Appl Energy 2014, 117, 11-29. [CrossRef]

10. Javanshir, A.; Sarunac, N.; Razzaghpanah, Z. Thermodynamic analysis of a regenerative organic Rankine cycle using dry fluids. Appl. Therm. Eng. 2017, 123, 852-864. [CrossRef]

11. Yamamoto, T.; Furuhata, T.; Arai, N.; Mori, K. Design and testing of the Organic Rankine Cycle. Energy 2001, 26, 239-251. [CrossRef]

12. Saleh, B.; Koglbauer, G.; Wendland, M.; Fischer, J. Working fluids for low-temperature organic Rankine cycles. Energy 2007, 32, 1210-1221. [CrossRef]

13. Dai, Y.P.; Wang, J.F.; Gao, L. Parametric optimization and comparative study of organic Rankine Cycle (ORC) for low grade waste heat recovery. Energy Convers. Manag. 2009, 50, 576-582. [CrossRef]

14. Chagnon-Lessard, N.; Mathieu-Potvin, F.; Gosselin, L. Geothermal power plants with maximized specific power output: Optimal working fluid and operating conditions of subcritical and transcritical organic Rankine cycles. Geothermics 2016, 64, 111-124. [CrossRef]

15. Walraven, D.; Laenen, B.; D'haeseleer, W. Comparison of thermodynamic cycles for power production from low-temperature geothermal heat sources. Energy Convers. Manag. 2013, 66, 220-233. [CrossRef]

16. Astolfi, M.; Romano, M.C.; Bombarda, P.; Macchi, E. Binary ORC (Organic Rankine Cycles) power plants for the exploitation of medium-low temperature geothermal sources-Part A: Thermodynamic optimization. Energy 2014, 66, 423-434. [CrossRef]

17. Clarke, J.; McLeskey, J.T., Jr. Multi-objective particle swarm optimization of binary geothermal power plants. Appl Energy 2015, 138, 302-314. [CrossRef]

18. Chen, Q.C.; Xu, J.L.; Chen, H.X. A new design method for Organic Rankine Cycles with constraint of inlet and outlet carrier fluid temperatures coupling with the heat source. Appl. Energy 2012, 98, 562-573. [CrossRef]

19. Borsukiewicz-Gozdur, A. Exergy analysis for maximizing power of organic Rankine cycle power plant driven by open type energy source. Energy 2013, 62, 73-81. [CrossRef] 
20. Diaz, A.R.; Kaya, E.; Zarrouk, S.J. Reinjection in geothermal fields-A worldwide review update. Renew. Sustain. Energy Rev. 2016, 53, 105-162. [CrossRef]

21. Vivian, J.; Manente, G.; Lazzaretto, A. A general framework to select working fluid and configuration of ORCs for low-to-medium temperature heat sources. Appl Energy 2015, 156, 727-746. [CrossRef]

22. Lazzaretto, A.; Manente, G. A new criterion to optimize ORC design performance using efficiency correlations for axial and radial turbines. Int. J. Thermodyn. 2014, 17, 173-181. [CrossRef]

23. Song, J.; Gu, C.W.; Ren, X.D. Influence of the radial-inflow turbine efficiency prediction on the design and analysis of the Organic Rankine Cycle (ORC) system. Energy Convers. Manag. 2016, 123, 308-316. [CrossRef]

24. Zhang, C.; Fu, J.L.; Kang, J.; Fu, W.C. Performance optimization of low-temperature geothermal organic Rankine cycles using axial turbine isentropic efficiency correlation. J. Braz. Soc. Mech. Sci. Eng. 2018, 40, 61. [CrossRef]

25. Perdichizzi, A.; Lozza, G. Design criteria and efficiency prediction for radial inflow turbines. In Proceedings of the ASME 1987 International Gas Turbine Conference and Exhibition, Anaheim, CA, USA, 31 May-4 June 1987; Paper No. 87-GT-231, p. V001T01A086. [CrossRef]

26. Le, V.L.; Kheiri, A.; Feidt, M.; Pelloux-Prayer, S. Thermodynamic and economic optimizations of a waste heat to power plant driven by a subcritical ORC (Organic Rankine Cycles) using pure or zeotropic working fluid. Energy 2014, 78, 622-638. [CrossRef]

27. Satanphol, K.; Pridasawas, W.; Suphanit, B. A study on optimal comparison of zeotropic working fluid in an Organic Rankine Cycle (ORC) for low grade heat recovery. Energy 2017, 123, 326-339. [CrossRef]

(C) 2018 by the authors. Licensee MDPI, Basel, Switzerland. This article is an open access article distributed under the terms and conditions of the Creative Commons Attribution (CC BY) license (http://creativecommons.org/licenses/by/4.0/). 